\title{
DiNÂMICAS DO GOZO E A CLÍNICA DAS TOXICOMANIAS
}

\author{
Fuad Kyrillos Neto \\ Luca Anaruma Ribeiro \\ Universidade Federal de São João del-Rei, São João del-Rei-MG, Brasil
}

\begin{abstract}
RESUMO
Este estudo teve por objetivo realizar uma pesquisa teórica em psicanálise sobre a clínica da toxicomania. Trata-se pesquisa teórica em psicanálise, visando a novos encadeamentos conceituais a respeito do tema. O consumo, que se apresenta como toxicômano, é atribuído a um gozo mortífero, dinâmica que visa à satisfação total das pulsões do Sujeito. Concluímos ao longo desse escrito que as dinâmicas de gozo representadas pelo Suplemento e Suplência possuem uma análise diferencial para a compreensão do consumo de drogas. Sugerimos, como contraponto, que o movimento de Alienação e Separação, metaforizado pela dinâmica do Fort-Da, é de grande valia na condução do processo clínico para o tratamento desse Sujeito.
\end{abstract}

Palavras-chave: Toxicomania; Gozo; Consumo.

\section{THE DYNAMICS OF JOUISSANCE AND CLINICAL CARE FOR DRUG ADDICTION}

\section{Abstract}

This study aimed to conduct theoretical research in psychoanalysis on the clinical care for drug addiction. It is theoretical research in psychoanalysis, aiming at new conceptual chains on the theme. The consumption that presents itself as drug addiction is attributed to a deadly enjoyment, a dynamic that aims at the total satisfaction of the individual's drives. We concluded how the dynamics of jouissance represented by Replacement and Supplement play a differential role in comprehending drug consumption. We suggest, as a counterpoint, that the Alienation and Separation movement, which worked as a metaphor in the Fort-Da dynamic, is of great value in conducting the clinical process for the treatment of these individuals.

Keywords: Drug addiction; Jouissance; Consumption.

\section{LA DINÁMICA DEL GOCE Y LA CLÍNICA DE DROGADICCIÓN}

\section{RESUMEN}

Este estudio tuvo como objetivo realizar una investigación teórica en psicoanálisis sobre una clínica de drogadicción. Se trata de una investigación teórica en psicoanálisis, apuntando a nuevas cadenas conceptuales sobre el tema. El consumo que se presenta como drogadicto se atribuye a un goce mortal, dinámica que apunta a la satisfacción 
total de los impulsos del Sujeto. Concluimos a lo largo de este artículo cómo la dinámica del goce representada por el Suplemento y el Reemplazo tiene un papel diferencial en la comprensión del consumo de drogas. Sugerimos, como contrapunto, que el movimiento de Alienación y Separación, metaforizado por la dinámica Fort-Da, es de gran valor en la conducción del proceso clínico para el tratamiento de estos sujetos. Palabras clave: Drogadicción; Goce; Consumo.

Visando a iniciar um diálogo a respeito de uma clínica das toxicomanias, primeiramente, devemos considerar o caráter histórico do próprio consumo de substâncias psicoativas (SPA). Apenas no século XX, o consumo de SPA, genericamente chamadas de drogas, foi considerado um problema social, delimitado por um discurso patologizante e por um discurso criminal. A convergência desses discursos inaugurou a política proibicionista, cujas premissas básicas são definidas por Fiore (2012): “O consumo de drogas é uma prática prescindível e danosa, o que justifica sua proibição pelo Estado; e a atuação ideal do Estado para combater as drogas é criminalizar sua circulação e seu consumo" (p. 10-11).

O caráter particular do consumo de drogas no Brasil traz consequências desiguais aos indivíduos, sendo mais problemático nas camadas mais pobres, nas quais, segundo diversas pesquisas, a maior parte do uso abusivo de SPA acontece (Dutra \& Arenari, 2016). Dessa forma, a parcela mais vulnerável da população, em que são mais proeminentes as questões relacionadas ao uso e abuso de substâncias, é a que mais sofre as consequências violentas do proibicionismo.

O número de encarceramentos vinculados ao porte de drogas é crescente. No período entre 2006 e 2010, o número de presos por tráfico de drogas saltou de 17.668 para 42.849 , valor $142 \%$ superior, sendo a maioria jovens negros pobres (Jesus et al., 2011). Devido à falta de rigor para estabelecer diferenças claras entre usuário e traficante, supostamente, qualquer pessoa que esteja portando substâncias ilegais pode ser presa. No entanto, essa medida tem maiores efeitos sobre "negros e mestiços, a maior parte da população pobre brasileira" (Coimbra \& Nascimento, 2003, p. 23).

A modalidade de encarceramento criminal como principal resolução para o problema das drogas também encontra seu correlato no campo da saúde. O isolamento social em centros de internação é a base de muitos tratamentos para usuários de drogas, perpetuando a visão proibicionista de que esses indivíduos são um risco em potencial para a sociedade, devendo, portanto, serem afastados para que medidas corretivas sejam aplicadas. A principal dessas medidas é a abstinência obrigatória, enquadrando esses sujeitos numa suposta normalidade social, em que o uso de drogas não ocorre, e alinhando-os às leis e à moral promovidas pelo Estado (Loeck, 2018).

Buscaremos divisar um saber-fazer clínico que permita ao Sujeito principiar a saída de um estado de alienação do discurso do tóxico para o desenvolvimento, mesmo que mínimo, de um discurso com algo de próprio, fator primordial para que haja condições de uma relação menos angustiante com a droga. Para isso, estabeleceremos, brevemente, o lugar do toxicômano na teoria psicanalítica, para, em seguida, analisarmos as potencialidades e limitações de uma clínica da toxicomania. 


\section{MÉTODO}

Procedemos a uma pesquisa teórica em psicanálise com o intuito de captar sua lógica interna e a coesão estrutural dos seus conceitos (Couto, 2010). Nossa intenção foi buscar, na teoria psicanalítica, a articulação interna de seus conceitos em um esforço de mostrar a relação de redes conceituais no que concerne às possibilidades de uma clínica psicanalítica das toxicomanias.

Escolhemos a revisão bibliográfica como principal fonte de informação para o desvelamento dos temas apresentados neste trabalho, justificados pela afirmação de Gallo (2012), na qual reconhece um sistema dialético "entre a vertente do acumulado estado da questão - e a do novo - desenvolvimento do trabalho" (p. 79-80). Enfatizamos que, através do trabalho documental de sistematizar o espaço ocupado pelo já criado, é possível compreendermos o espaço deixado para o novo. Esse modo de pesquisa, segundo Galeano (2007), permite ao pesquisador alcançar um grande leque de informações relacionadas ao tema, possibilitando melhor sistematização dos dados dispersos em diversas publicações e formando o substrato necessário para definir conceitualmente as dinâmicas de gozo envolvidas na clínica da toxicomania.

\section{A INCIDÊNCIA DO TÓXICO NA OBRA FrEUdIANA}

A apropriação da temática das drogas pela psicanálise encontra ressonância na obra freudiana. Em seu livro "O mal-estar na civilização", Freud (1930/2010) se debruça, de forma mais direta, sobre o fenômeno do uso de entorpecentes, indicando que, devido às restrições culturais e instâncias repressoras da psique, o sujeito é levado à renúncia da satisfação total de seu desejo, gerando um mal-estar inerente a essa condição e tornando fundamental que cada Sujeito recorra a medidas consideradas por ele como paliativas com o intuito de auxiliar a suportar tal angústia.

Dessa maneira, conforme Freud, o recurso tóxico aparece como "o método mais grosseiro, embora também o mais eficaz" (p. 86), pois possui efeito de alívio imediato sobre o corpo. Sem desconsiderar os efeitos químicos que a droga pode exercer sobre o Sujeito, Freud aponta sua função como panaceia, algo que é capaz de aliviar o sofrimento psíquico do Sujeito através da dessensibilização de processos psíquicos normalmente desprazerosos.

Freud (1930/2010), ainda nesse livro, esboça a multiplicidade de sentidos que o uso de substâncias pode ter para o Sujeito. Em um dos casos, sua função é vista como mais um recurso dentre diversos que o Sujeito lança mão em sua busca pela felicidade, reconhecendo sua importância como objeto de investimento "tão altamente apreciado que tantos indivíduos como povos lhe concederam lugar permanente na sua economia libidinal" (p. 86).

Ao se referir às drogas como um paliativo, ou seja, como algo a mais, é delineada pelo autor sua função compensatória no programa civilizatório, que se apresenta para o Sujeito como um grande mercado de investimento objetal. Este oferece possibilidades quase ilimitadas, a fim de que cada um tente lidar com um déficit de satisfação causado pela economia pulsional em que o Sujeito é inserido ao adentrar a cultura. Devido às suas restrições, a cultura condena os que nela estão inseridos a lidar com um resto de seu próprio gozo não realizado, que, todavia, é vivenciado como desejo (Santiago, 2001). 


\section{AS DROGAS E SUA PLÁSTICA MOVIMENTAÇÃO NO CIRCUITO LIBIDINAL}

Este fator econômico exercido pela civilização é interpretado por Lacan como um mais-de-gozar, em sua função de renúncia ao gozo sob efeito do discurso Ele é contabilizado pelo Sujeito como a possibilidade de satisfação através de relações objetais substitutas, que permitam um alinhamento dinâmico com seu desejo, ao mesmo tempo em que demonstram a renúncia do Sujeito a um gozo primordial (Ribeiro, 2009).

Já o uso tido em sua forma "crônica" é apontado por Freud (1930/2010) como desdobramento extremado da busca pela satisfação do Sujeito. Este, ao recusar a satisfação plena da pulsão, ocasiona um rompimento do circuito pulsional, pois este se molda através de um movimento sucessivo de investimento e contrainvestimento em objetos, uma tentativa contínua de apreender aquilo que falta, le petit a (Lacan, 1964/1985).

Ao aceitar como referência simbólica a Lei, o Sujeito aceita a castração que o aparta de gozar de um objeto total, ainda que este gozo se de modo ilusório. Ao considerarmos esse circuito como o bordejamento, ao mesmo tempo se cria esse furo nesse circuito, resultante da castração do Sujeito, podemos compreendê-la como responsável por organizar as modalidades de satisfação pulsional vivenciada por ele. Portanto, a quebra desse circuito seria a negação do gozo fálico através do preenchimento artificial desse buraco, o qual passa a não ter mais borda que permita a fruição pulsional (Lacan, 1964/1985).

Isso é possível, de acordo com Gianesi (2002), uma vez que "No discurso de cada sujeito a droga pode surgir operando essa plástica movimentação" (p. 128). Por isso, devemos considerar que, em alguns casos, tal plasticidade permite ao Sujeito localizar seu vínculo libidinal com a droga fora do gozo fálico, burlando os limites da castração representados pela falta. Para Lacan (1976), tipifica-se como um uso toxicômano, que é entendido como uma tentativa de fugir à angústia associada à lógica fálica. Lógica de que o Sujeito nada quer saber, pois, invariavelmente, o colocaria frente a frente com a traumática descoberta da falta no Outro, que é vivida como insuportável desamparo.

Essa tentativa, porém, é impossível de ser lograda, já que o acesso à dimensão do gozo pleno somente pode ocorrer antes da entrada do Sujeito no campo da linguagem, lançando-o num processo contínuo de manutenção desse semblante. Quando a droga é consumida até o fim, algo inevitável, cria-se no Sujeito a demanda de ir em busca de mais, o que faz com que o ciclo recomece. Por sua natureza paradoxal, o ato de consumo prescinde da mediação da palavra, perante o qual se impõe, então, a dimensão do fazer no Real, sem sentido, momento, portanto, quando o Sujeito não está (Torossian, 2002).

Nesse ponto, torna-se evidente que as diversas formas de investimento libidinal que o Sujeito pode estabelecer com o tóxico passa pela sua capacidade de suportar determinada modalidade de gozo. Afirmação afiançada por Ribeiro (2009) ao pontuar que "os critérios capazes de diferenciar os tipos de usuários e formas de uso existentes só podem dizer respeito à modalidade de gozo" (p. 53). Ao adotarmos as dinâmicas do gozo como um dos principais parâmetros para diferenciar as formas pelas quais cada um se utiliza das drogas, assentimos à centralidade que o Sujeito possui dentro do campo analítico. Portanto, para a psicanálise o objeto droga é secundário, pois o sujeito é colocado como principal e responsável diante de suas escolhas, cujo sentido somente é 
dado a posteriori a partir da função que este sujeito estabelece junto ao esforço de tamponar sua falta.

Dessa forma, o fenômeno de uso e abuso de substâncias, encarado pela psicanálise como pertencendo ao campo da linguagem, é junto a tantos outros uma função do discurso, sempre posterior à estrutura gramatical que determina a organização libidinal do sujeito, fundado a partir do trauma da castração (Jorge, 2002, p. 25). Esse ponto permanece essencial no caminho analítico que pretende auxiliar o Sujeito na construção de um discurso que dê algum sentido ao seu desejo e, por consequência, um outro lugar de gozo (Dor, 1991). Neste ponto, devemos ficar atentos a quais significantes o objeto droga está articulado, permitindo que a particularidade do Sujeito apareça nessa associação, de modo a dar ao analista a chance de entrever o mal-estar que está enlaçado ao Sujeito previamente ao uso do recurso tóxico.

Assim, ao adotarmos como referencial a clínica psicanalítica, devemos levar em conta que o ato de se intoxicar parte de uma escolha do Sujeito frente ao seu desejo (Leite, 2005) representado através de seu discurso. Esta implicação do sujeito frente ao seu desejo é fruto da própria falta que o constitui: o complexo de castração. Ao ser apartado da possibilidade de satisfazer seu gozo através dos caprichos maternos, o infans é apresentado à dimensão da Lei, cuja marca é o traço fundante de uma estrutura que demanda significado; portanto, significante.

A partir da primeira oposição significante - presença-ausência - gerada pela interdição, esse traço funcionará como referencial simbólico para a construção de um Saber, uma cadeia significante que pretende tamponar a angústia do trauma. Ao assentir ao destino imposto pela castração, o Sujeito se lança à dimensão do desejo, circunscrevendo a falta nos limites de suas possibilidades de investir em objetos substitutos, cuja satisfação será parcial, evitando, no entanto, o perigo da castração (Jorge, 2002, p. 25). Dessa maneira, ao nos debruçarmos sobre o fenômeno das toxicomanias, e para além dele, o consumo de drogas em geral, devemos considerar esse objeto como parte de um discurso maior que implica a todo momento o Sujeito (Dor, 1991).

Em diversos momentos ao longo do conflito entre sistemas e instâncias que marcam o Sujeito como cindido, o recurso à droga pode servir como remendo para um saber que apresenta rasgos em sua estrutura, furos por onde a angústia poderia brotar, denunciando a falha em significar a falta do Sujeito (Lacan, 1969-1970/1992).

O tóxico, então, pode aparecer vinculado ao sintoma, o qual se apresenta como aquilo que emerge desse saber esburacado, marcando o discurso com a insistência repetitiva de um gozo vinculado ao recalcado (Gianesi, 2002). Isso demonstra que, ao nos debruçarmos sobre a relação que o Sujeito cria entre droga e sintoma, a repetição que pode ser presumida de um consumo contínuo não necessariamente deve ser interpretada como sintoma, já que o que se repete ao longo do processo analítico se apresentará como significante na fala do analisando. A compulsão à repetição se apresenta, pois, como meio de gozo. Essa satisfação mortífera é extraída do apagamento do novo por ele mesmo, cujo efeito no discurso é afastar o Sujeito da necessidade de saber algo sobre isso de que fala. Dessa forma, o sintoma comporta em si uma dupla impossibilidade: a realização do desejo que alude ao trauma e a tentativa de anular esse fato mediante a repetição (Freud, 1920/2013, p. 14).

Ao nos referirmos à realidade discursiva do sintoma, levamos em conta sua natureza como mensagem cifrada de conteúdos inconscientes, que se revela através do paradigma dos atos falhos (Leite, 2000). É somente ao se referir à droga em análise que 
o Sujeito a representa em sua realidade particular, como parte de uma cadeia significante, cujas falhas, que irrompem como chistes e atos falhos, deixam entrever o conteúdo recalcado, que é ligado à substância através de um deslize metonímico, uma troca de significantes, visando, justamente, a ocupar o lugar de um indizível (Gianesi, 2002). Nesse caso, a droga pode se apresentar no discurso analítico antes mesmo que uma verdadeira queixa possa ser formulada pelo Sujeito, a ponto de haver grande resistência em formulá-la perante o analista para além das influências desse objeto que ocupa determinada centralidade (Gianesi, 2002).

\section{A DROGA E SUAS MODALIDADES DE GOZO}

Para compreendermos os mecanismos pelos quais a droga pode se articular à falta estruturante do Sujeito, recorremos a Torossian (2002). Esta propõe o Suplemento e a Suplência como duas modalidades de gozo que servem de suporte discursivo para representar a relação do Sujeito e seu sintoma com a droga.

No primeiro caso, é considerado pela autora que o referido objeto assumiria a forma de um acessório narcísico, algo que diga do Sujeito sem que, entretanto, faça parte dele. É um refúgio para um princípio de prazer que não pode encontrar amparo no gozo fálico, cujo limite precisa constantemente ser reeditado, para comportar novos significantes que deem continuidade à construção de um discurso sobre o desejo (Gianesi, 2002). O Sujeito, ao lançar mão desse recurso, busca garantir que não será devorado pelo grande Outro e, com isso, ter seu desejo desmantelado. Para tanto, mantém, junto de si, um objeto que medeia esse encontro, colocando-se a serviço como ferramenta para lidar com a descontinuidade entre o Eu e o Outro estabelecida pela linguagem (Torossian, 2002).

A pressuposição de um Outro é uma importante característica a ser percebida ao longo da fala do analisando, indicando uma tentativa de separação, apontada por Freud (1905/2016) como uma das principais tarefas do Sujeito ao longo de sua estruturação psíquica, favorecendo a criação de laços e identificações fora do seio familiar. A inclusão do Outro em seu circuito pulsional, mediante uma triangulação com a substância, permite que o laço social aconteça de modo que novos objetos passíveis de investimento libidinal apareçam, passando a compor, ao lado da droga, significantes em uma cadeia por onde o desejo flui.

O discurso de Suplemento indica a consideração do Sujeito pela interdição de um gozo, que, de outra forma, se faria ilimitado e mortífero. A erotização pulsional, ao mesmo tempo em que responde à demanda de significação pelo Outro, promove a emergência do novo, através de novas possibilidades de configuração da cadeia significante, sublinhando o lugar da droga como acessório metafórico na resolução do falta-a-ser de cada um (Gianesi, 2002).

Todavia, dando continuidade à ideia de Torossian (2002), a dimensão do discurso tóxico pode assumir um caráter especial de Suplência, colocando em questão, para o Sujeito, a própria relevância da alteridade como necessária à regulação, gradualmente excluindo a dimensão do Outro (Le Poulichet, 1990). Ao evitar que a oposição significante fundamental representada pelo Eu-Outro ocorra, o Sujeito nega a descontinuidade imposta pela castração, movimento que se aproxima de uma dita toxicomania (Torossian, 2002). 
O Sujeito busca, então, se desprender do referencial fálico, elegendo o princípio de prazer em detrimento do princípio de realidade como principal forma de investimento pulsional. Ao incorrer numa tentativa imperfeita de reprodução do estado fusional mãe-bebê, o Sujeito acaba por se alienar no significante droga, que se amalgama ao Ser do sujeito, confundindo-se com este. A intoxicação passa a representar um papel central na economia libidinal do Sujeito, que, num estado suposto de completude, abdica da lógica fálica como mediadora de seu desejo irrompendo num gozo sem limites, o qual cria um curto-circuito pulsional, uma vez que o consumo passa a ser um fim em si mesmo. Pode-se causar, dessa maneira, a rasura da ausência materna, inscrevendo em seu lugar uma outra: a do tóxico (Ribeiro, 2009).

Esse tipo de relação, cujo efeito passa pela ausência de simbolização, dificulta a sexualização do investimento libidinal, primeira forma de separação objetal através da significação do corpo, transformando o corpo do Sujeito em corpo feito ferramenta (Torossian, 2002). Este se realiza na mediação de um consumo desenfreado, tentando, a todo custo, evitar a descontinuidade do real e, com isso, a queda do objeto perdido.

O controle sobre o abandono através do objeto substituto reflete, por outro lado, a tentativa de impedir que a interdição seja revivida e a falta se instale. Segundo Gianesi (2002), ao ser posicionada como substituto da figura materna ausente, a droga ocupa o vazio deixado por aquilo que um dia se teve e posteriormente foi perdido; portanto, um lugar de onde o desejo emanaria. A substituição da oposição significante pela homogeneidade, cuja igualdade mascara a falta, dá espaço para um gozo desfalicizado, chamado por Lacan (1959-1960/1997) de mortal, pois, à medida que não traz a marca inscrita da Lei, dá espaço para que a pulsão de morte se volte contra o corpo do próprio Sujeito, que se torna a única barreira contra seu gozo ilimitado.

Sem um referencial fálico que permita ao Sujeito se identificar com o significante mestre de sua cadeia discursiva, este incorre num estado de Alienação. Lacan (1964/1985) o define como uma identificação massiva do Sujeito no campo do Outro, ficando, a partir disso, incapaz de dar sentido para sua cadeia significante através de um referencial introjetado.

O discurso de Suplência, no qual o sujeito se encapsula como um bebê em ventre materno, se torna o novo referencial através do qual pode gravitar, tornando-o, assim, um meio de identificação: sou toxicômano. De acordo com Gianesi (2002), esse "fato que deve ser entendido pelo analista como próprio do campo das identificações" (p. 131). Esta identificação totalizante, que impede o Sujeito de ser algo além, ganha status de escolha, equacionada pelo Sujeito como Saber sobre si, adotando o discurso da droga como tamponamento da falta causada por um significante recalcado.

A cristalização do significante da droga, anteriormente descrita, pode demonstrar a baixa aderência à função da Lei paterna, que falha em manter o Sujeito identificado ao Falo. Essa questão é reconhecida por Olievenstein (1933/1985) como um ponto imprescindível no processo analítico. Ele postula que há necessidade de que haja, por parte do paciente, um processo de ressignificação das instâncias reguladores do desejo, pois "Parte do papel do analista dentro desta clínica é buscar uma maior harmonia entre a lei real e a lei imaginária" (p. 21). Essa assertiva encontra paralelos entre uma das funções da Lei pontuadas por Freud (1920/2013) em "Além do princípio do prazer", que aponta a tentativa de elaboração da castração pela criança como importante momento para a entrada do Sujeito na dimensão do gozo fálico, momento quando os limites iniciais de seu desejo são construídos. 
Considerando o exposto, podemos contemplar uma repartição entre um modo de gozo regido pelos desígnios da lei, operando como Suplemento, e um outro, para além da logica fálica. O gozo do Outro, que toma o sujeito pelo real do corpo, passa a representar, segundo Lacan "a substância do corpo, com a condição de que ela se defina apenas como aquilo de que se goza" (1972-1973/1985, p. 35), resistindo, assim, as limitações impostas pela linguagem, necessárias a significação. Deste modo, o acesso a este outro modo de gozo, exige do sujeito a transgressão da lei simbólica, operando para isso, a dinâmica de Suplência, fazendo com que o sujeito toxicômano seja tomado como instrumento do gozo do Outro, visando completá-lo (Santiago, 2001).

\section{AS TOXICOMANIAS NA DINÂMICA DO FORT-DA}

Foi em seu livro, "Além do Princípio de Prazer", que Freud (1920/2013) observou, pela primeira vez, na metaforização inscrita no ato de brincar, a tentativa do Sujeito de ser para além do Outro. Nessa obra, o autor evoca a imagem de seu neto, uma criança que brinca com um carretel, encontrando-se nos estágios iniciais do complexo de Édipo. Num primeiro momento, pronunciando a palavra "Fort" ("vai" em português), lança o objeto à distância até sair de sua vista. No momento seguinte, puxa o carretel e pronuncia, então, a palavra " $\mathrm{Da}$ " (similar a "vem").

Freud (1920/2013) aponta este momento inicial, quando o carretel e a criança estão juntos, como correlato ao estado fusional mãe-bebê. Em seguida, ao produzir o desaparecimento do objeto, lançando-o para longe, a criança presentifica a falta materna a ser enfrentada, criando um sentido para esse momento. A rememoração do trauma pode, então, ter lugar, porém com a possibilidade de o Sujeito se colocar de forma ativa frente à situação, "transferindo a experiência desagradável para um de seus companheiros de brincadeira e, dessa maneira, vinga-se num substituto" (p. 9). Através dessa fala é salientada a importância da transferência, que permite outro desfecho possível, dando possibilidade para que o Sujeito transcenda o estado de desamparo anterior.

Lacan (1964/1985), por sua vez, nos indica, em “O seminário, livro 7: a ética da Psicanálise", que o Fort-Da pode ser tomado como um marco teórico para a introdução do Sujeito no campo do Simbólico, uma primeira tentativa de dar significado às suas relações objetais. O autor reinterpreta a dinâmica do Fort-Da como parte de um processo de Alienação e Separação.

Desse modo, podemos situar o estado do infans prévio ao Fort-Da como consonante à teoria da Alienação, "como a primeira operação essencial em que se funda o sujeito" (Laurent, 1997, p. 43), em que este é totalmente dependente do discurso do Outro, que lhe doa significantes para o desenvolvimento de sua primeira nomeação como Sujeito.

Porém, este processo de subjetivação a partir do discurso do Outro é limitado, na medida em que não há coincidência absoluta entre Sujeito e Outro, gerando um resto não representável, efeito próprio da linguagem que afasta ideia e coisa. Dessa forma, a fratura entre Ser e sentido, cuja totalidade será somente parcialmente abarcada pelo discurso, irá marcar o Sujeito como essencialmente faltoso.

O segundo momento subsequente à Alienação será nomeado por Lacan (1964/1985) como Separação, sendo marcado por uma mudança de status do Sujeito perante o Outro, que passa a perceber na alteridade a mesma falta que o constitui. 
Através da constante alternância entre presença e ausência maternas, a criança percebe que não é o único objeto de desejo, voltando-se, conforme o autor, ao nonsense do desejo do Outro, que é recebido pela criança como um enigma: "O que o Outro deseja".

Assim, a promessa de formação de identidade passa a se encontrar fora do discurso do Outro, que é incapaz de responder sobre o desejo do Sujeito, visto que ele próprio deseja algo para além de si. Para responder a esse enigma, na tentativa de elaborar essa falta que não pode ser totalmente preenchida pelo campo do Outro, o Sujeito rearranjará seus significantes seus próprios significantes com o objetivo de compor um discurso que dê conta de apaziguar a situação de desamparo (Lacan, 19611962/2003).

Dessa forma, podemos encontrar no jogo do Fort-Da pistas a respeito do manejo clínico essencial para auxiliar o sujeito toxicômano em seu processo analítico. Ao incluirmos a relação do Sujeito com a droga como parte do tratamento, em oposição a tratamentos que exigem a abstinência, devemos considerar a dinâmica pulsional que o tóxico evoca como uma ferramenta usada pelo Sujeito para tentar elaborar conteúdos e conflitos inconscientes.

Ao nos atermos a um dos tempos do Fort-Da, aquele no qual o carretel está longe da criança, poderemos encontrar uma consonância ao consumo de drogas representado pelo discurso de Suplemento, um modo de satisfação que suporta a dimensão da Lei (Torossian, 2002), o gozo fálico, levando em conta um Outro como referência na construção de sua relação com o objeto tóxico.

Ao lançar mão do recurso tóxico, o Sujeito busca garantir que não será totalmente dissolvido em suas relações com o Outro, mantendo, junto de si, um objeto que medeia esse encontro. Assim como o carretel, a substância psicoativa pode apresentar aspectos de uma prótese narcísica, algo que diga do Sujeito sem que, no entanto, faça parte dele. Nas palavras de Lacan (1964/1985): "Esse carretel... é alguma coisinha do sujeito que se destaca embora ainda sendo bem dele, que ele ainda segura" (p. 66).

A busca pela suposta satisfação plena perdida por intermédio do consumo de droga efetuaria uma operação no campo imaginário, funcionando como uma garantia para o Sujeito de que, mesmo que seu desejo seja capturado pelo Outro, algo lhe resta (Torossian, 2002). Por sua vez, esse resto simboliza um mais-de-gozar, um modo de satisfação que pode encontrar amparo nas relações sociais, as quais são regidas pelos desígnios do Falo. Essa forma de satisfação garante ao Sujeito um alívio da angústia gerada por esse encontro com o Outro, representado nas relações sociais.

Por conseguinte, ao adotarmos o Fort-Da como referencial, a operação imaginária lograda pelo tóxico pode ser interpretada como anteparo, um suplemento pulsional, para que o Sujeito possa suportar a angústia de significar os limites da castração. Tais limites precisam, constantemente, serem reeditados para comportar os novos objetos advindos do meio social, que passam a compor, ao lado da droga, significantes em uma cadeia, na qual o Sujeito pode deslizar de momento a momento, constituindo novas identificações que o aproximem de seu desejo (Gianesi, 2002).

Na outra ponta dessa dinâmica, momento quando a criança está com o carretel, encontra-se o uso de Suplência, em que a droga é inserida como contraparte primordial para que um semblante de completude ocorra, tentativa de recriar o estado fusional vivenciado pelo par mãe-bebê.

Ao se recusar a jogar o carretel, o Sujeito se nega a entrar no jogo significante do Fort-Da, mantendo-se numa fase anterior ao jogo propriamente dito, que se inicia 
quando o objeto é mandado para longe. O Sujeito, que aderiu a um uso caracterizado como toxicômano, rejeita a falta do objeto de desejo, buscando manter seu estado de alienação a qualquer preço, mesmo que, para isso, na ausência da figura materna, seja necessário se filiar a uma Outra (outra mãe), representada pelo discurso da Droga (Melman, 1992), como forma de manter o carretel. Ao encarnar na droga seu objeto de desejo perdido, sempre poderá recorrer a ele como forma de evocar a realização imaginária - de seu desejo castrado.

O estado de Alienação em que o Sujeito toxicômano se encontra pode ser interpretado como uma questão relacional. Ao se recusar a suportar a angústia das sucessivas idas e vindas, desinvestimentos e investimentos que formariam seu circuito desejante, o Sujeito opta por uma relação dual, quase hipnótica, com a droga, refugiando-se longe de um Outro que possa lhe apontar sua falta. O Suplemento, ou a toxicomania, funciona como um discurso que ganha status de Saber, preenchendo a descontinuidade entre Sujeito e objeto (Gianesi, 2002). Isso ocorre através de uma identificação massiva: o Sujeito passa a não saber onde termina e o objeto começa, passando a se nomear através do próprio objeto, essencialmente "aquele que o usa", aquele que o tem.

Nesse caso, parte do processo clínico consiste em permitir que a separação possa ocorrer, propiciando que o Sujeito se ligue a outros significantes para a construção de um discurso, que sirva como referencial para dizer algo de si, delineamento fundamental para um outro modo de gozar. De acordo com Miller (1992): "Em todos os casos, a possibilidade de análise passa pelo esforço de desfazer a identificação bruta 'eu sou toxicômano"" (p. 20).

Ao nos recordarmos do princípio de conversão proposto por Freud (1920/2013), em que a criança transforma, através da repetição, a angústia de uma situação passiva em satisfação ativa no brincar, podemos compreender o Fort-Da como uma alternativa que pode permitir a lenta precipitação do Sujeito para fora de um estado alienatório suportado pelo discurso da Droga. Isso indica que o próprio espaço analítico é profícuo para que a oposição presença-ausência ocorra, situação que poderá ser vivenciada pelo Sujeito como ativa, através da convocação a significar uma relação não abarcada pelo discurso da Droga, por intermédio de um Outro figurado pelo analista.

Segundo Olievenstein (1933/1985), um vínculo transferencial é uma parte significativa do processo desenvolvido em análise, que visa a auxiliar o Sujeito na realização de seu jogo desejante; em suas palavras: "Caberá a clínica desmascarar este jogo" (p. 16). Um dos potenciais alcances clínicos de conceber o Fort-Da no trabalho com toxicômanos reside na possibilidade de reintroduzir, gradualmente, a dimensão da Lei para o Sujeito, que, através da droga, até então a negava. No entanto, a mediação da palavra permite a invocação de uma angústia, momento quando a droga, como o carretel, pode, momentaneamente, sair de vista, dando espaço para que a falta tenha lugar como uma perda onde se ganha. Aos poucos, a associação livre que brota dos interstícios de um discurso enrijecido pelo tóxico passa a converter, vagarosamente, um gozo em Saber, tornando a significação da falta um trabalho que pode ser suportado pelo Sujeito.

A interrogação a respeito de quem é esse que consome provoca no Sujeito a tentativa de representar algo com o intuito de obter uma resposta. Ao trazer para o tratamento a ideia de Sujeito não inerente ao consumo, mas sim fruto de diversas relações, entre elas a com o tóxico, os efeitos de assujeitamento cedem espaço a uma inclusão de si, permitindo que o Sujeito possa considerar, de forma mais ampla, os elementos ligados à sua relação com a droga (Olievenstein \& Parada, 2002). 
Desse modo, a falta opera como ponto de partida para a construção de um novo discurso. É nessa medida que Lacan (1957/1998) pontua a criança do Fort-Da como exemplo de como uma cadeia significante pode ser rearranjada através de uma "ação que destrói o objeto que ela faz aparecer e desaparecer na provocação antecipante de sua ausência e de sua presença" (p. 320). A significação pode, assim, acontecer, circunscrevendo a falta ao encená-la para si mesmo. Quando é representada por meio do conteúdo que surge na associação livre e endereçada através do discurso a uma representação de si, a volta (Dáá) se torna o significante gerado pela recém-formada simbolização da oposição de significantes eu e um outro eu - um Outro. A possibilidade de ressignificação do objeto se dá através da representação da presença de sua ausência através da palavra, que aponta para o que não está lá. Podemos falar, então, em uma humanização do desejo como desvelamento do Sujeito. Isso ocorre quando o objeto deixa de ser visto como algo de que se foi privado, para ser incorporado como falta constituinte desse Sujeito que emerge e é fruto desta (Lacan, 1957/1998).

A partir dessa relação objetal, que é simbolizada pela transferência em análise, uma mudança de posição do Sujeito frente ao Outro pode ocorrer, movimentando o Sujeito através de sua cadeia significante (Raíces, 1992). Isso propicia a articulação de novos significantes que possam abarcar outros objetos presentes na economia libidinal do Sujeito, delineando, novamente, os contornos do circuito pulsional envolto de uma estrutura fálica.

\section{CONSIDERAÇÕES FINAIS}

Reiteramos que, ao considerarmos a dimensão do Sujeito, optamos por explorar, ao longo deste escrito, a diferença entre duas formas de consumo encontradas ao longo da pesquisa teórica em psicanálise: o Suplemento e a Suplência. Essas dinâmicas, porém, não pretendem abarcar o entendimento a respeito do consumo de drogas, passível de diversas significações e efeitos sempre conjugadas a um momento histórico e cultural.

Para isso, recorremos às dinâmicas de gozo propostas por Lacan, cuja relevância é justificada, visto se tratar de uma experiência com a dinâmica gozosa do Sujeito, que aponta para algo muito além do princípio do prazer, qual seja, o gozo mortal em sua faceta repetitiva. Essa foi uma das formas encontradas, por nós, para compreender o que poderia levar um sujeito a se ocupar, e eventualmente se fixar, em um modo de consumo em detrimento de outros.

Esse modo seria marcado pela tentativa de criar uma relação de Suplência, sustentada por um gozo total, "o que permite romper o casamento do sujeito com o pequeno pipi” (Lacan, 1976, p. 268). Ou seja, uma relação que se inscreva fora do campo da lei, driblando, dessa forma, uma relação com a lei.

A respeito dessa dinâmica considerada pelo autor como mortífera, indagamos a respeito da problemática do Falo: como a Lei pode ser articulada no caso de um consumo toxicômano, que, ao prescindir de um Outro, tenta ignorar o complexo de castração?

Propomos, como resultado deste trabalho, que a dinâmica de Alienação e Separação (Lacan, 1964/1985), representada pelo Fort-Da, pode ser um importante aliado para o tratamento clínico desse Sujeito, que se resguarda contra a Lei simbólica, 
pretendendo, a todo custo, evitar as consequências da castração por intermédio de uma parceria tóxica.

Dessa maneira, uma estratégia para a condução dessa clínica consistiria em nos atentarmos para a dinâmica do Fort-Da, permitindo que a separação entre Sujeito e objeto ocorra, mesmo que de forma parcial. Através da transferência, o setting analítico proporciona ao Sujeito a experiência de uma relação com um Outro castrado, representado pela figura do analista.

É, pois, a partir da falta que se atualiza no processo transferencial que a dinâmica do Fort-Da pode ter prosseguimento, permitindo que a oposição presençaausência possa se dar, momento quando o Sujeito, eventualmente, pode efetuar uma nova amarração de seu discurso, abrindo espaço para simbolizar sua angústia. No Fortda, a simbolização da Lei entra em evidência, visto que, ao se deparar com a interdição do desejo, o sujeito se vale do jogo como primeira ferramenta para criar um discurso que se propõe a abarcar os limites impostos a seu gozo, através de significantes que deem conta de elaborar a angústia da castração.

Com este estudo demonstramos a possibilidade de um saber-fazer na clínica das toxicomanias, que considere as dinâmicas do gozo. Por intermédio do manejo deste gozo, a transição do sujeito para além de um estado alienatório junto a droga, sustentado pelo gozo desenfreado da Suplência faz-se possível. Ao localizar suas possibilidades de satisfação nos limites de seu discurso, podemos antever a passagem do sujeito para uma dinâmica de gozo que se aproxime das modulações do Suplemento, introduzindo assim, uma redução do mal-estar entre o Sujeito e a instância da Lei.

\section{REFERÊNCIAS}

Coimbra, C., \& Nascimento, M. C. (2003). Jovens pobres: O mito da periculosidade. In P. C. P. Fraga, \& J. A. S. Iulianelli (Orgs.), Jovens em tempo real (pp. 13-22). DP\&A.

Couto, S. (2010). Quatro modalidades de pesquisa em psicanálise. In F. Kyrillos Neto, \& J. Moreira (Orgs.), Pesquisa em Psicanálise: transmissão na Universidade (pp. 59-80). EdUEMG.

Dor, J. (1991). Estruturas e clínica psicanalítica. Taurus-Timbre.

Dutra, R., \& Arenari, B. (2016). A construção social da condição de Pessoa: premissas para romper o círculo vicioso de exclusão e uso problemático do crack. In J. Souza (Org.), Crack e exclusão social (pp. 191-208). Senad/MJ.

Fiore, M. (2012). O lugar do Estado na questão das drogas: O paradigma proibicionista e as alternativas (N. 92, pp. 9-21). Novos Estudos Cebrap. https://doi.org/10.1590/S0101-33002012000100002

Freud, S. (2016). Três ensaios sobre a teoria da sexualidade. In S. Freud, Obras Completas, volume 6: Três ensaios sobre a teoria da sexualidade, Análise fragmentada de um caso de histeria ("O caso Dora") e outros textos (1901-1905) (pp. 13-16). Companhia das Letras. (Original publicado em 1905)

Freud, S. (2013). Além do princípio do prazer. In S. Freud, Obras Completas, volume 14 : História de uma neurose infantil ("O homem dos lobos"), Além do princípio do prazer e outros textos (1917-1920) (pp. 120-179). Companhia das Letras. (Original publicado em 1920) 
Freud, S. (2010). O mal-estar na civilização. In S. Freud, Obras Completas, volume 18: O mal-estar na civilização, Novas conferências introdutórias à Psicanálise e outros textos (1930-1936) (pp. 13-122). Companhia das Letras. (Original publicado em 1930)

Galeano, M. E. (2007). Estrategias de investigación social qualitativa: El giro en lamirada. La Carreta. https://doi.org/10.2307/j.ctvdf06h7

Gallo, H. (2012). Del método y la investigación psicoanalítica. In M. E. Ramírez, \& H. Gallo, El psicoanálisis y la investigación en la Universidad (pp. 77-103). Grama.

Gianesi, L. (2002). Considerações psicanalíticas sobre a toxicomania, o objeto droga e $o$ sujeito da psicanálise. (Dissertação de Mestrado), Instituto de Psicologia, Universidade de São Paulo, São Paulo.

Jesus, M. G. M., Oi, A. H., Rocha, T. T., \& Lagatta, P. (2011). Prisão Provisória e Lei de Drogas: Um estudo sobre os flagrantes de tráfico de drogas na cidade de São Paulo. Núcleo de Estudos da Violência - USP. Disponível em: http://www.nevusp.org/downloads/down254.pdf

Jorge, M. A. C. (2002). Saber, verdade e gozo: Leituras de O seminário, livro 17, de Jacques Lacan. Rios Ambiciosos.

Lacan, J. (1998). Subversão do sujeito e dialética do desejo no inconsciente freudiano. In J. Lacan, Escritos (pp. 807-842). Jorge Zahar Editor. (Original publicado em 1957)

Lacan, J. (1997). O Seminário, livro 7: A ética da psicanálise. Jorge Zahar. (Original publicado em 1959-1960)

Lacan, J. (2003). A identificação: Seminário 9. Centro de Estudos Freudianos do Recife. (Original publicado em 1961-1962).

Lacan, J. (1985). O seminário, livro 11. Os quatro conceitos da psicanálise. Jorge Zahar. (Original publicado em 1964)

Lacan, J. (1992). O seminário, livro 17: O avesso da psicanálise. Jorge Zahar. (Original publicado em 1969-1970).

Lacan, J. (1985). O Seminário, livro 20: mais, ainda. Jorge Zahar. (Original publicado em 1972-1973)

Lacan, J. (1976). Journées des cartels de l'École Freudienne de Paris. Lettres de l'École Freudienne, (18), p. 262-270.

Laurent, E. (1997). Alienação e Separação I. In R. Feldstein, \& B. Fink, M. Jaanus (orgs.), Para ler o seminário 11 de Lacan (pp. 31-41). Jorge Zahar.

Le Poulichet, S. (1990). Toxicomanías y psicoanálisis: Las narcosis del deseo. Amorrortu.

Leite, E. A. F. (2005). Drogas - Concepções, imagens: Um comentário sobre dependência a partir do modelo usual de prevenção. Annablume.

Leite, S. (2000). Psicanálise lacaniana: Cinco seminários para analistas kleinianos. Iluminuras.

Loeck, J. F. (2018). Comunidades terapêuticas e a transformação moral dos indivíduos: Entre o religioso-espiritual e o técnico-científico. In M. P. G. Santos (Org.), Comunidades terapêuticas: Temas para reflexão (pp. 77-100). Ipea.

Melman, C. (1992). Alcoolismo, delinquência, toxicomania: uma outra forma de gozar. Escuta.

Miller, A. (1992). Para una investigación sobre el goce autoerótico. In E. Sinatra, D. Sillitti, \& M. Tarrab (comp.), Sujeto, Goce y Modernidade: Fundamentos dela Clínica (Vol. 1, pp. 13-22). Atuel-TyA. 
Olievenstein, C. (1985). O destino do toxicômano (M. D. Grandy, Trad.). Aimed. (Original publicado em 1933)

Olievenstein, C., \& Parada, C. (2002). Droga, adolescentes e sociedade: Como um anjo canibal. Instituto Piaget.

Raíces, G. (1992). La forma del síntoma en la drogadicción. In E. Sinatra, D. Sillitti, \& M. Tarrab (Comp.). Sujeto, Goce y Modernidad: Fundamentos de la Clínica (Vol. 1, pp. 62-75). Atuel-TyA.

Ribeiro, T. C. (2009). Que lugar para as drogas no sujeito? Que lugar para o sujeito nas drogas? Uma leitura psicanalítica do fenômeno do uso de drogas na contemporaneidade. Ágora: Estudos em Teoria Psicanalítica, 12(12), 333-346. http://dx.doi.org/10.1590/S1516-14982009000200012

Santiago, J. (2001). A droga do toxicômano: Uma parceria cínica na era da ciência. Zahar.

Torossian, D. (2002). Construção das toxicomanias na adolescência: travessias e ancoragens. EDUNISC.

Submetido: $15 / 03 / 2021$

Reformulado: 20/04/2021

Aceito: $28 / 04 / 2021$

\section{Sobre os autores:}

Fuad Kyrillos Neto é Doutor em Psicologia Social pela Pontifícia Universidade Católica de São Paulo (PUC/SP). Docente do Departamento de Psicologia da Universidade Federal de São João del-Rei (UFSJ).

Luca Anaruma Ribeiro é graduando em Psicologia pela Universidade Federal de São João del-Rei (UFSJ). Bolsista do Programa Institucional de Bolsas de Iniciação Científica da UFSJ/CAPES.

Correspondência: fuadneto@ufsj.edu.br 